\title{
Parasitic Contamination Incidences at Inspection of Harvested Springbok (Antidorcas marsupials) and Gemsbok (Oryx gazelle) in Namibia
}

\author{
Magwedere $\mathrm{K}^{1,3 *}$, Hemberger $\mathrm{HY}^{1,3}$, Khaiseb $\mathrm{S}^{2}$, Hoffman LC ${ }^{3}$ and Dziva $\mathrm{F}^{3,4}$
}

${ }^{1}$ Division of Animal and Veterinary Public Health, Directorate of Veterinary services, P.O Box 28, Hospital Street, Mariental, Namibia

${ }^{2}$ Central Veterinary Laboratory, Ministry of Agriculture, Water and Forestry, P. Bag 13187, Windhoek, Namibia

${ }^{3}$ Department of Animal Science, University of Stellenbosch, Private Bag X1, Matieland, Stellenbosch, 7602, South Africa

${ }^{4}$ Division of Microbiology, Institute for Animal Health, Compton, Berkshire RG20 7NN, United Kingdom

\begin{abstract}
Little work has been conducted on parasitic infestation of harvested wild game at game abattoirs in Namibia The aim of this study was to assess parasitic contaminations that occur in two commonly harvested Namibia game species. We examined springbok (Antidorcas marsupialis) and gemsbok (Oryx gazelle) carcasses for parasite infestation and rectal contents from eviscerated gut for worm egg counts among other routine inspection protocols. A filarial worm, Skrjabinodera kuelzii was found in 104 out of 540 carcasses harvested from separate 3 farms and then submitted for cutting and deboning. These filarial worms were predominantly between the hindquarter muscles, pelvis region and sometimes in renal fat. As a precautionary measure, these carcasses were condemned whole or part depending on the level of infestation. The larvae and filarial worms were only found in springbok but not in gemsbok carcasses. Worm eggs of strongyle, Strongyloides papillosus, Toxocara spp, Trichuris spp and coccidia were found in variable numbers in both springbok and gemsbok faeces, indicating a potential risk of transmission to other susceptible species in the ecosystem. The unusual deep muscle contamination of springbok carcasses by S. kuelzii are significant findings which should be considered during routine meat inspection of harvested wildlife.
\end{abstract}

Keywords: Game; Meat inspection; Skrjabinodera kuelzii; Gemsbok; Parasite; Springbok

\section{Introduction}

Wildlife farming is increasingly becoming integrated into the mainstream meat industry for food security and income generation in most Southern African countries thus positioning the wildlife industry on a different platform from its traditional past [1]. In recent years, Namibia has witnessed a remarkable recovery and increase in wildlife populations. The number of small communal conservancies, which bring immense benefits to many rural communities, has spiraled significantly in many parts of the country. Surveys indicate that Springbok (Antidorcas marsupialis), Oryx (Oryx gazelle) and Mountain Zebra (Equus zebra) populations increased over 10 times between 1982 and 2000 with about $80 \%$ of these located on privately owned farms or freehold conservancies [2]. However, the characteristics of soil, vegetation, spatial distribution of resources and presence of multispecies, such as predators, all influence the dynamics of the host-parasite system [3]. In many parts of the free ranging farms, cattle, sheep, and goats graze together and carnivores such as jackals are common in some areas. Sheep are by far the most numerous livestock species in the southern part of Namibia, and along with goats have the greatest opportunity for livestock-wildlife transmission by grazing remote land frequented. Due to the nature of this important emerging wildlife industry, slaughter practices tend to differ in many aspects from standard procedures applicable in slaughterhouses of livestock species. Small ruminant wildlife are slaughtered by free bullet and immediately bled then eviscerated whilst suspended on mobile line hangers. However, meat inspection procedures conform to standard practices for other food-producing animals and likewise, further investigations are invariably undertaken on all seized carcasses.

The changing ecosystems impact on wildlife populations and their susceptibility to pathogens they carry which underlines an absolute requirement for a systematic and thorough meat inspection process in order to prevent transmission to humans [4,5]. Parasitic infection is not uncommon in springboks [6-12]. In game species examined elsewhere, a numbers of helminth species and new host records for several species of nematodes were reported (http://www.bisoncentre.com). Worm burdens ranging between 2,954 and 71,790 have been reported in South African wildlife $[8,9]$. Most reviews of animal health monitoring systems mention wildlife disease surveillance only in passing because of the difficulties of establishing population estimates (denominator data) for defining rates, such as disease incidence, or the obstacles to developing systematic surveillance programs coordinating with human disease surveillance [13]. Here, we evaluate the inspection incidence of parasites in springbok (Antidorcas marsupialis) and gemsbok (Oryx gazelle) carcasses for parasite infestation and rectal contents from eviscerated gut for worm egg counts. These data also provide a baseline for possible future assessments of the distribution of parasites among Namibian ungulates.

\section{Materials and Methods}

\section{Pre-slaughter health assessment}

Animals from two farms located $100 \mathrm{~km}$ apart in different districts of Hardap and Karas regions of Namibia were initially presented for slaughter in 2005. A further 9251 springbok and gemsbok animals sourced from eight different farms were presented for slaughter between

*Corresponding author: Kudakwashe Magwedere, Divisions of Veterinary Public Health, Directorate of Veterinary services, P.O Box 28, Hospital Street, Mariental Namibia, Tel: +264 63 242972; Fax: +264 63242971; E-mail: gwedas@yahoo. co.uk

Received April 02, 2012; Accepted May 14, 2012; Published May 20, 2012

Citation: Magwedere K, Hemberger HY, Khaiseb S, Hoffman LC and Dziva F (2012) Parasitic Contamination Incidences at Inspection of Harvested Springbok (Antidorcas marsupials) and Gemsbok (Oryx gazelle) in Namibia. J Veterinar Sci Technol 3:113. doi:10.4172/2157-7579.1000113

Copyright: (c) 2012 Magwedere K, et al. This is an open-access article distributed under the terms of the Creative Commons Attribution License, which permits unrestricted use, distribution, and reproduction in any medium, provided the original author and source are credited. 
April 2009 and August 2010. Assessment of the general physical and health status of these animals was undertaken by an experienced hunter. This was accomplished by assessing the animal's response to attempted capture. Briefly, this involved a precise estimation of escape distances and flight zones of animals at night. Sick or exhausted animals, generally had shorter escape distances $(30-100 \mathrm{~m})$ and flight zones compared to healthy animals which were always greater than 120 m.

\section{Slaughter and meat inspection process}

Animals were shot with a free bullet and immediately suspended on to mobile hangers for bleeding and evisceration. Bleeding and evisceration were completed within $30 \mathrm{~min}$ of shooting, and carcasses were transported to a field dressing station for an initial health inspection. Carcasses passing initial inspection were transported under chilled conditions to a slaughterhouse for skinning and final inspection as described previously $[14,15]$. The carcasses underwent a meat inspection process conforming to guidelines stipulated in the European Commission regulation [14]. A detailed schedule of the inspection process is illustrated in South African game regulations [16]. Specific features requiring serious consideration included the following; general body condition, efficiency of bleeding, degree of gross contamination, colour, odour, external parasitic infestation, bruising and injuries. Any condemned whole or part of the carcass was seized and subjected to further detailed examination which included macro- and microscopic examination [14].

\section{Faecal worm egg counts}

Approximately 50 grams of faecal contents from the posterior part of the rectum were randomly collected from each of the adult health gemsbok and springbok harvested between April 2009 and August 2010 from different farms. Each pooled sample consisted of five subsamples collected from five animals. Forty five pooled samples from springbok and twelve from gemsbok were collected. The samples were refrigerated at $4^{\circ} \mathrm{C}$ within $30-60$ min after collection until analysis. Parasites eggs were quantified using the Wisconsin double centrifugal sugar flotation method [17]. Briefly, five grams of mashed faecal material with a small grinder was weighed and placed in a $15 \mathrm{ml}$ glass beaker. $13 \mathrm{ml}$ of water was then added to fill up the glass beaker and stirred thoroughly with a spatula until a mash material was formed. The slurry was then passed through a tea sieve and funnel into a test tube while pressing on the remaining material. The tubes were balanced before centrifugation. The samples were then centrifuged at $1500 \mathrm{rpm}$ for 10 minutes. After centrifuging, the supernatant was removed, with care being taken not to lose the fine sediment of the pelleted material. The tube was then filled approximately half way with sugar solution and the pellet was dispersed using a glass rod. The tube was then topped off with sugar solution until a meniscus was formed, and a $22 \times 22 \mathrm{~mm}$ cover slip was placed on top. The samples were then centrifuged at $1500 \mathrm{rpm}$ for 10 minutes. Gently, the cover slips were transferred to slides and the entire cover slip was examined. Counts were expressed as per gram of faeces.

\section{Identification of parasitic larvae}

The larvae infested meat samples were preserved in $10 \%$ formalin and $70 \%$ alcohol before referring them to the Central Veterinary Laboratory in Windhoek. Identification was to the level of genus and where possible to species level, using keys and illustrations based on gross morphological features and microscopic examination using a light microscope. In the identification of $S$. kuezii, the worms were carefully separated from the muscle tissues using dissection equipment into sterile petri-dishes. The worms were preserved in 70\% alcohol. Identification was based on microscopic examination using a light microscope [18].

\section{Results and Discussion}

Shooting individual game animals opportunistically on encounter is not an ideal sampling method, and can be prone to biases; for example, towards animals with parasites of high intensity. Therefore, in our study, we assumed that shooting did not result in the selection of thinner animals or those with high intensities of parasites, assuming that group size itself is independent of parasite intensity and based on the post mortem results. During a routine inspection of 279 springbok carcasses, no helminths and or arthropods parasite larvae associated abnormalities or pathological lesions were detected at post mortem inspection although some carcasses, whole or in part, were condemned for aesthetic reasons (bruising, bad bleeding and general gross contamination). Subsequent detailed examination of the passed carcasses during deboning revealed parasite larvae on 39 carcasses more concentrated in the hindquarter muscles (Musculus biceps femoris, M. gluteus and M. semitendinosus) and seldom in the Longissimus dorsi muscles. Thirty-nine out of 279 springbok carcasses were condemned for aesthetic reasons. Notably, the infested carcasses comprised 36 from the $1^{\text {st }}$ farm in Hardap and three were from the 2nd farm in Karas region. Characteristically, the larvae were approximately 7-10 $\mathrm{mm}$ long with a few possessing a distinct dark red pigmentation, whilst the majority was creamy in color. Subsequent detailed laboratory examination presumed the larvae to be early or late 1st stage larvae of Chrysomya or Musca species. We were unable to perform further molecular identification of the larvae to species level and future molecular analysis is recommended for definitive identification. Intriguingly, a further examination of 9251 springbok carcasses from 5 different farming units failed to detect these larvae. Interestingly, it is well-acknowledged that phenotypic identification is best undertaken with third instar larvae [19]. To our knowledge, the deep muscle contamination of carcasses by these parasitic larvae is the first report and hence should be considered during meat inspection of game meat.

Whilst we considered these observations in 39 springbok carcasses to be significant, we could not explain why such larvae were not detected in a further 9251 springbok carcasses from 5 different geographical regions over a four year-period. However, a filarial parasite S. kuelzii was detected at a prevalence rate per farm of $19 \%$ on one farm and $100 \%$ on two farms respectively in 700 springbok carcasses brought in for cutting and deboning. The farms were separated from each other by at least $50 \mathrm{~km}$. S. kuelzii in 104 springbok carcass, was predominantly located in the pelvic cavity fascia, muscle fascia and renal fat. Figure 1 shows $S$. kuelzii located on pelvic fascia. As a precautionary measure, these carcasses were condemned whole or in part depending on the level of infestation. Subsequent investigations after 3 months confirmed the pelvic region to be the predilection site of these worms. Very little is known about the life cycle of this filarial worm which belongs to the family Onchocercidae. An unidentified haematophagous arthropod, most likely a dipteran insect as for other Onchocercidae, is believed to be the transmitting vector. It is widely accepted that Diptera flies are mechanical and biological vectors of human enteric pathogens and hence should be of great concern from the sanitary and health point of view $[20,21]$. Occupation of a specific niche within the host to evade immune mechanisms seems to be a paramount survival technique. The significance of these worms is not apparent, they seem not to cause pathological lesions in the peritoneum and no swollen lymph 
Citation: Magwedere K, Hemberger HY, Khaiseb S, Hoffman LC and Dziva F (2012) Parasitic Contamination Incidences at Inspection of Harvested Springbok (Antidorcas marsupials) and Gemsbok (Oryx gazelle) in Namibia. J Veterinar Sci Technol 3:113. doi:10.4172/2157-7579.1000113

Page 3 of 4

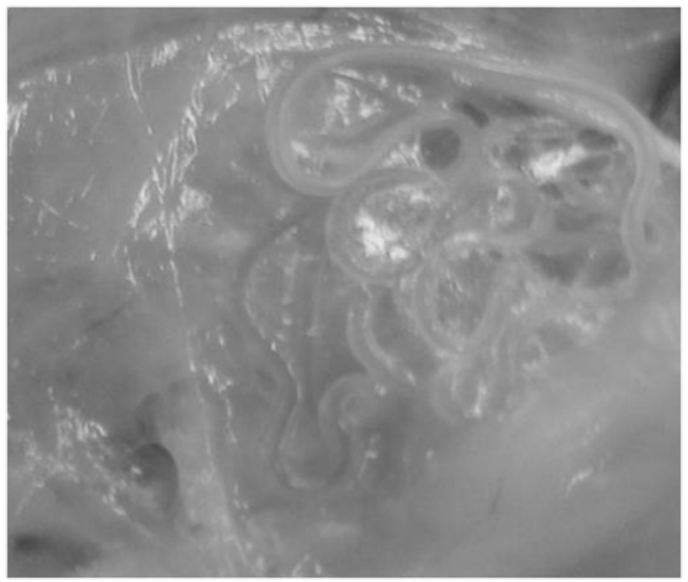

Figure 1: Skrjabinodera kuelzii adult worms inhabiting the pelvic muscle fascia of the springbok.

nodes were detected in the affected animals. However, the numbers and location of worms may vary from farm to farm. On the other hand, absence of Skrjabinodera kuelzii could be related to the spatial distribution of Diptera flies, which is poorly characterized in Namibia, inclusive of the regions from where the 9251 carcasses originated and furthermore, climatic variation affects the prevalence, geographical distribution and more importantly, the survival of free-living larval stages of parasites [7,22-24]. Typically, in one farm 1-20 worms were found in the pelvic area only while on another farm 15-30 worms were consistently found in the pelvic and inter-muscular connective tissue of hindquarter muscles. Interestingly, the parasite dies within 1 hour after the death of the host suggesting that it probably relies on oxygenated circulating blood or homeostatic body temperature. The parasite was restricted to 3 farms possibly reflecting the distribution of the vector. Undoubtedly, more work is required to define the clinical significance, the biology and epidemiology of this parasite in wildlife in order to inform on safety of meat derived from such sources. Infestation with filarial worms is not uncommon in ruminant wildlife species though. Skrjabinodera kuelzii was originally described as Filaria kuelzii. Filaria kuelzii is now a synonym of Skrjabinodera kuelzii. Filaria kuelzii was described in three antelopes (Philantomba maxwelli), which harboured S. kuelzii $[25,26]$. The parasites were found in the intramuscular connective tissue of the back and pelvis region including subcutaneous tissue and microfilariae could be demonstrated on the blood smears. Dirofilaria asymmetrica has been described in the common duiker (Sylvicapra grimmia) in South Africa, but the site of infection was not specified. Chabaud and Rousselot synonymised this species with $S$. kuelzii, and described specimens from the intermuscular connective tissue from the black-backed duiker (Cephalophus dorsalis castaneus) in the then Belgian Congo [18,27]. S. tanganyikae was originally described as Gazellofilaria tanganyikae from the peritoneal cavity and mesentery of Thomson's gazelle (Gazella thomsoni) and further studies showed that this parasite also occurred in the pelvic cavity of Grant's gazelle (Nanger-granti) [28,29].

Rectal contents of both gemsbok and springbok were found to contain variable numbers of different helminth eggs. Whilst the gemsboks harboured eggs of strongyle, Trichuris spp and coccidia, the springboks were also infested with Trichuris spp, Toxocara $s p p$ and Strongyloides papillosus in addition those found in gemsboks. Detailed worm egg burdens are given in Table 1. Parasite richness and prevalence

\begin{tabular}{|c|c|c|c|}
\hline Animal species & Parasitic species & $\begin{array}{l}\text { Worm egg count } \\
\text { per gram of faeces }\end{array}$ & $\begin{array}{l}\text { Number of positive } \\
\text { cases expressed as a } \\
\text { percentage of the total } \\
\text { number examined }\end{array}$ \\
\hline \multirow{3}{*}{ Oryx gazella } & Strongyle & $200-2000$ & 57.14 \\
\hline & Trichuris spp & $100-1000$ & 7.14 \\
\hline & Coccidia oocyst & $300-1000$ & 28.57 \\
\hline \multirow{7}{*}{$\begin{array}{l}\text { Antidorcus } \\
\text { marsupialis }\end{array}$} & Strongyle & $>200$ & 24 \\
\hline & $\begin{array}{l}\text { Strongyle papil- } \\
\text { losus }\end{array}$ & $11-200$ & 7 \\
\hline & Toxocara spp & $1-10$ & 2 \\
\hline & Trichuris spp & $1-5$ & 5 \\
\hline & Coccidia oocyst & $1-1000$ & 44 \\
\hline & $\begin{array}{l}\text { Unidentified } \\
\text { muscle larvae }\end{array}$ & $\mathrm{N} / \mathrm{A}$ & 0.4 \\
\hline & $\begin{array}{l}\text { Skrjabinodera } \\
\text { kuelzii }\end{array}$ & N/A & 77.14 \\
\hline
\end{tabular}

Table 1: Prevalences of parasites eggs detected in farmed Oryx gazelle and Antidorcus marsupialis in Namibia at slaughter.

in wild animals can be used as indicators of population and ecosystem health and a number of parasitic species from the genus Toxocara and Trichuris pose a potential anthropozoonotic transmission risk [30-32]. The significance of the egg counts in this study is not clearly discernible as the carcasses were apparently average body condition but SubSahara Africa is famous for its great mixed variety of distinctive animals with carnivores, or meat-eating animals, include the wild dogs, lion, leopard, cheetah, hyena, jackal, and mongoose [33]. Consistent with this, worm egg loads have been reported to remain constant in healthy animals under normal conditions but increase considerably upon the induction of stressful conditions such as drought, disease and serious injury [34]. In impala, worm egg loads can rise from 20000 to 60000 per animal during drought periods, but the damage to the host largely depends on the composition and dynamics of the worm population [7]. The composition of the worm load is also dependent on the type of vegetation and its condition as determined by seasonal factors $[34,35]$. A significant difference in the worm burden has been reported between browsers and grazers. Kudus in the Kruger National Park where they predominantly graze had a mean worm egg count of 2251 compared to 339 in those mainly browsing in Etosha National Park in Namibia [34]. However, gastrointestinal nematode infections are known to reduce growth rates in domestic ruminants and decreased body mass and condition have been reported in parasitized animals in a range of wildlife species, including ruminants [36].

\section{Conclusion}

Regulatory authorities should consider the possibility of deep muscle contamination by larvae during routine meat inspection of game meat. Furthermore, a better understanding of the ecology and spatial distribution of haematophagous arthropods and other dipteral species in Namibia is urgently needed to determine the dynamics of these larvae and filarial worms in free ranging wildlife and domestic species. Lastly, an urgent need exists to define the significance of $S$. kuelzii in food-producing wildlife.

\section{Acknowledgements}

We wish to thank Dr Kerstin Junker, Onderstepoort Veterinary Institute for identifying the Skrjabinodera kuelzii and critical review of this manuscript, technical parasitology staff from Central Veterinary laboratory (CVL) Namibia for the faecal worm egg counts. Many thanks goes to Dr Tolmay from Mariental State Veterinary office, Dr A.L Hager from Central Veterinary laboratory (CVL) and the technica staff of the Directorate of Veterinary services, Animal Health and Public Health division for their technical assistance. 
Citation: Magwedere K, Hemberger HY, Khaiseb S, Hoffman LC and Dziva F (2012) Parasitic Contamination Incidences at Inspection of Harvested Springbok (Antidorcas marsupials) and Gemsbok (Oryx gazelle) in Namibia. J Veterinar Sci Technol 3:113. doi:10.4172/2157-7579.1000113

\section{References}

1. Vertefeuille J, Benn J (2005) Conserving through conservancy: Managing land and wildlife in Namibia. World Wildlife Fund.Science in Africa.

2. Weaver LC, Skyer P (2003) Conservancies: Integrating Wildlife Land-Use Options into the Livelihood, Development, and Conservation Strategies of Namibian Communities.

3. Artois M, Blancou J, Dupeyroux O, Gilot-Fromont E (2011) Sustainable contro of zoonotic pathogens in wildlife: how to be fair to wild animals? Rev sci tech 30: $733-743$

4. Mukaratirwa S, Magwedere K, Matenga E, Foggin CM (2001) Transmission studies on Trichinella species isolated from Crocodylus niloticus and efficacy of fenbendazole and levamisole against muscle L1 stages in Balb C mice. Onderstepoort J Vet Res 68: 21-25.

5. http://journals2005.pasteur.ac.ir/IJP/35(11-12).pdf

6. http://www.animalhealthaustralia.com.au/wp-content/uploads/2011 SWF30-16FINAL11Jul07.pdf

7. http://upetd.up.ac.za/thesis/available/etd-12032009-194518/unrestricted /02sec1-chapter2.pdf.

8. De Villiers LL, Liversidge R, Reinecke RK (1985) Arthropods and helminths in springbok (Antidorcas marsupialis) at Benfontein, Kimberley. Onderstepoort $J$ Vet Res 52: 1-11.

9. Horak IG, Meltzer DG, De Vos V (1982) Helminth and arthropod parasites of springbok Antidorcas marsupialis in the Transvaal and Western Cape Province. Onderstepoort J Vet Res 49: 7-10.

10. Ortlepp RJ (1961) 'n Oorsig van Suid-Afrikaanse helminte veral met verwysing na die wat in ons wildherkouers voorkom. Tydskrif vir Natuunvetenskappe 1 203-212.

11. Round MC (1968) Checklist of the helminth parasites of African mammals of the orders Carnivora, Tubulidentata, Proboscides, Hyracoidea, Artiodactyla. Bucks CommonwealthAgriculture bureau 38: 4-252.

12. Young E, Zumpt F, Basson PA, Erasmus B, Boyazoglu PA, et al. (1973) Notes on the parasitology, pathology and biophysiology of springbok in the Mountain Zebra National Park. Koedoe 16: 195-198.

13. Childs JE (2007) Pre-spillover prevention of emerging zoonotic diseases: what are the targets and what Are the tools? CTMI 315: 389-443.

14. Game Regulations draft (2010) Department of Agriculture, South Africa: 1-43.

15. Maja M (2006) Veterinary Procedure Notice No VPN/09/2006/02. Department of Agriculture, South Africa.

16. European Union Regulation 854/2004 Specific 228 rules for the organization of official controls on products of animal origin intended for human consumption. OJEU L226: 83-127.

17. Goodman D, Haji HJ, Bickle QD, Stoltzfus RJ, Tielsch JM, et al. (2007) A Comparison of Methods for Detecting the Eggs of Ascaris, Trichuris, and Hookworm in Infant Stool, and the Epidemiology of Infection in Zanzibar Infants. Am J Trop Med Hyg 76: 725-731.

18. Chabaud AG, Rousselot R (1956) Pygarginema africana n. sp. (Nematoda,
Ascaropsinae) parasite of an African cephalophus. Ann Parasitol Hum Comp 31: $248-254$

19. OIE (2008) New World Screwworm (Cochliomyia hominvorax) and Old World Screwworm (Chrysomya bezziana). OIE Terrestial Manual: 265-275.

20. Baumgartner DL (1993) Review of Chrysomya rufifacies (Diptera: Calliphoridae). J Med Entomol 30: 338-352.

21. Mbilu TJNK, Siyalo RS, Kimbita EN, Onditi SJ (2007) Studies on the importance of the face Fly Musca sorbens at Kambala Village, Mvomero District, Morogoro, Tanzania. Livestock Research for Rural Development 19 (4).

22. Mas-Coma S, Valero MA, Bargues MD (2008) Effects of climate change on animal and zoonotic helminthiases. Rev Sci Tech 27: 443-457.

23. Patz JA, Graczyk TK, Geller N, Vittor AY (2000) Effects of environmental change on emerging parasitic diseases. Int $\mathrm{J}$ Parasitol 30 : 1395-1405.

24. Van den Bossche P, Coetzer JA (2008) Climate change and animal health in Africa. Rev Sci Tech 27: 551-562.

25. Khalil LF, Gibbons LM (1975) Gazellostrongylus lerouxi Yeh, 1956 from antelopes in East Africa and its relation to the genus Paracooperia Travassos, 1935. J Helminthol 49: 271-279.

26. http://www.archive.org/stream/revuezoologiquea05bru $\mathrm{x}$ revuezoologiquea-05brux_djvu.txt

27. Quentin JC (1969) Biological cycle of Pterygodermatites desportes (Chabaud and Rousselot, 1956) Nematoda Rictulariidae. Ann Parasitol Hum Comp 44:

47-58.

28. Sachs R, Southwood PD, Shattock TRE, Simmonds RC, Greathead FJ, et al. (1976) Origins of pest, parasite, disease and weed problems. 18th Symposium of the British Ecological, Bangor: 12-14

29. Liang-Sheng $Y$ (1956) On a collection of helminths from Thomson's Gazelle, Gazella thomsoni, from Tanganyika. J Helminthol 29: 203-228.

30. Okulewicz A, Perec-Matysiak A, Buńkowska K, Hildebrand J (2012) Toxocara canis, Toxocara cati and Toxascaris leonina in wild and domestic carnivores. Helminthologia 49: 3-10

31. Dado D, Izquierdo F, Vera O, Montoya A, Mateo M, et al. (2012) Detection of zoonotic intestinal parasites in public parks of Spain. Potential epidemiological role of microsporidia. Zoonoses Public Health 59: 23-28.

32. Teichroeb JA, Kutz SJ, Parkar U, Thompson RC, Sicotte P (2009) Ecology of the gastrointestinal parasites of Colobus vellerosus at Boabeng-Fiema Ghana: possible anthropozoonotic transmission. Am J Phys Anthropol 140: 498-507.

33. UNEP (2002) Regionally Based Assessment of Persistent Toxic Substances.

34. Bothma J du P (2006) Game range management. In: ( $\left.4^{\text {th }} e d n\right)$ Van Schaik Uitgewers Publications, Pretoria, South Africa.

35. Boomker J, Horak LC, De Vos V (1986) The helminth parasites of various artiodactylids from some South African nature reserves. Onderstepoort J Vet Res 53: 93-102.

36. Morgan ER, Shaikenov B, Torgerson PR, Medley GF, Milner-Gulland EJ (2005) Helminths of saiga antelope in Kazakhstan: implications for conservation and livestock production. J Wildl Dis 41: 149-162. 